\title{
Liraglutide as Add-on to Oral Antidiabetic Agents or Insulin in Routine Practice of Patients with Type 2 Diabetes
}

\author{
Christian Anholm¹, Hans Albert Frandsen², Eva Christina Højgaard Sigfusson ${ }^{3}$, \\ Henrik Vestergaard ${ }^{3,4}$, Sten Madsbad ${ }^{1}$ \\ ${ }^{1}$ Department of Endocrinology, Hvidovre Hospital, Copenhagen, Denmark \\ ${ }^{2}$ Department of Internal Medicine, Amager Hospital, Copenhagen, Denmark \\ ${ }^{3}$ Department of Endocrinology, Herlev Hospital, Copenhagen, Denmark \\ ${ }^{4}$ The Novo Nordisk Foundation Center for Basic Metabolic Research, Faculty of Health and Medical Sciences, \\ University of Copenhagen, Copenhagen, Denmark \\ Email: canholm@youmail.dk
}

Received 20 April 2014; revised 16 May 2014; accepted 22 May 2014

Copyright (C) 2014 by authors and Scientific Research Publishing Inc.

This work is licensed under the Creative Commons Attribution International License (CC BY).

http://creativecommons.org/licenses/by/4.0/

(c) (i) Open Access

\begin{abstract}
Aims: To evaluate in a real-word routine-care practice the effect of liraglutide as add-on treatment in type 2 diabetic patients treated with oral antidiabetic agents and/or insulin. Methods: A retrospective study from 3 outpatient clinics in Copenhagen, Denmark, of all patients $(n=534)$ initiating treatment with liraglutide. 346 patients were treated $\geq 3$ months. Excluded from analysis were: 107 patients changing from exenatide and 83 due to lack of clinical response or adverse events. Results: In 149 patients liraglutide was add-on to oral antidiabetic agents, most often metformin plus sulfonylurea $(n=86)$. Mean follow-up: $7.3 \pm 3.0$ months. HbA1c reduction: $1.3 \% \pm 1.5 \%$ $(15 \pm 16 \mathrm{mmol} / \mathrm{mol})$ from a baseline of $8.7 \% \pm 1.5 \%(71 \pm 16 \mathrm{mmol} / \mathrm{mol})$. Weight reduction: $-3.5 \pm$ $4.9 \mathrm{~kg}$ from $105.2 \pm 21.3 \mathrm{~kg}$. Sulfonylurea treatment was stopped/dose reduced in $57 \%$ of these patients. In 114 patients liraglutide was add-on to insulin. Mean follow-up: 7.0 \pm 3.1 months. HbA1c reduction: $0.8 \% \pm 1.2 \%(8 \mathrm{mmol} / \mathrm{mol})$ from a baseline of $8.7 \% \pm 1.5 \%(71 \pm 16 \mathrm{mmol} / \mathrm{mol})$. Weight reduction: $-5.1 \pm 4.9 \mathrm{~kg}$ from $109.2 \pm 22.1 \mathrm{~kg}$. Baseline insulin dose of $83 \pm 59 \mathrm{U} /$ day was reduced by $28 \pm 36 \mathrm{U} /$ day. Insulin therapy could be stopped in $19 \%$ of these patients. Conclusions: Effects on HbA1c and weight of liraglutide as add-on to oral antidiabetic agents were not different from results previously published in randomised trials. Adding liraglutide to existing insulin regimens is an attractive treatment strategy in obese type 2 diabetic patients.
\end{abstract}

\section{Keywords}

Type 2 Diabetes, GLP-1 Receptor Agonist, Liraglutide, Insulin Treatment 


\section{Introduction}

Liraglutide is a once-daily glucagon-like peptide-1 (GLP-1) receptor agonist indicated for treatment of type 2 diabetes in combination with oral antidiabetic agents [1]. Liraglutide has a half-life of 11 - 13-hour offering 24hour glucose control [2]. Liraglutide was in Denmark already from time of approval widely used "off label” as add-on to insulin to improve glycaemic control and to promote weight loss in obese type 2 diabetic patients. This combination treatment was inspired by the previous clinical experience by adding exenatide twice daily (BID) to insulin treatment in people with type 2 diabetes.

GLP-1 receptor agonists mimic the biological effects of GLP-1 and improve insulin secretion and inhibit glucagon release in a glucose dependent manner, which protect against hypoglycaemia [3]. Furthermore, the GLP-1 receptor agonists delay gastric emptying, especially the short acting exenatide BID, while during treatment with liraglutide this effect seems to wane off after few days of treatment [4]. An important consideration when selecting anti-hyperglycaemic treatment is effect on weight [5]. The GLP-1 receptor agonists also induce weight loss by reducing caloric intake [2] [6]. In the clinical trials with liraglutide the weight loss has on the average been about 2 - 4 kilograms (kg), and about one quarter of the patients with the greatest weight loss have lost on the average 6 - $7 \mathrm{~kg}$, while one quarter of the patients have not lost weight or even gained weight [7]. The reduction in HbA1c with liraglutide in clinical controlled trials of the LEAD (Liraglutide Effect and Action in Diabetes) programme was $0.8 \%$ to $1.5 \%$ (9 to $16 \mathrm{mmol} / \mathrm{mol}$ ) in patients with an average baseline HbA1c of $8.2 \%$ to $8.5 \%$ (66 to $69 \mathrm{mmol} / \mathrm{mol}$ ) [2] [8]. In patients with a mean baseline HbA1c of $8.5 \%$ and $9.8 \%$ (69 and 84 $\mathrm{mmol} / \mathrm{mol}$ ), the mean reduction was $1.4 \%$ and $2.3 \%$ (15 and $25 \mathrm{mmol} / \mathrm{mol})$, respectively [2] [8]. The reduction in HbA1c was in most studies greater or at least similar to oral antidiabetic drugs and insulin glargine [1] [2]. The side effects of GLP-1 receptor agonists are primarily nausea and in few patients vomiting [2], which in most patients are mild and transient [2]. In clinical trials less than 5\% of patients discontinued GLP-1 receptor treatment because of adverse effects [2].

Type 2 diabetes is associated with overweight and is characterized by a complex pathophysiology and with gradual deterioration of glycaemic control over time because of deteriorating beta-cell function [9]. The treatment strategy includes the sequential addition of oral antidiabetic agents, and insulin therapy is frequently required to control hyperglycaemia [10]. This is typically achieved by adding basal insulin or premix insulin, often in combination with metformin, since studies have demonstrated both less weight gain and dose of insulin when the two agents are used together [10] [11]. Insulin treatment is associated with risk of hypoglycaemia [10], and despite intensification of insulin regimens, a substantial proportion of the patients are unable to achieve the glycaemic target [12] [13]. The GLP-1 receptor agonists have complementary effects on glucose control compared with insulin, and side effects of insulin treatment as hypoglycaemia and weight gain might be mitigated in combination with a GLP-1 receptor agonist [14]. Recently the use of exenatide twice daily as add on to insulin glargine and addition of insulin detemir to liraglutide was approved by the Food and Drug administration (FDA) and European Medicines Agency (EMA). The once daily short acting GLP-1 receptor agonist lixisenatide was approved by EMA in 2013, which also includes use in combination with basal insulin.

Very few studies have investigated the use of the GLP-1 receptor agonist liraglutide during real life in routine clinical practice. In the present study the efficacy of liraglutide from time of approval was investigated in consecutive patients starting liraglutide OD in three academic outpatient clinics.

\section{Material and Methods}

Three outpatient clinics in Copenhagen, Denmark, participated in the study. By use of clinical databases all patients with type 2 diabetes, who had started treatment with liraglutide were identified. Information about age, sex, weight, height, body mass index and HbA1c was collected. In patients, who had stopped treatment with liraglutide the reasons were outlined. The endpoints HbA1c, weight and BMI are only reported for patients followed for at least 3 months during treatment with liraglutide. Patients, who had changed from exenatide BID to liraglutideOD were excluded from the analyses.

Treatment decisions were made by the individual physician, who had no prespecified treatment protocols for initiating treatment with liraglutide.

\section{Statistics}

Microsoft Office Excel (2010) was used for statistical analyses. Data were tested for normality and parametric 
statistics used. Data are means \pm SD (standard deviation) if not otherwise stated. Changes in variables from baseline to follow up date were evaluated with paired $t$ test. Pearson's correlation coefficient was used to determine correlation between change in weight and change in HbA1c and change in weight and change in total daily insulin dose.

\section{Results}

\subsection{Attrition}

A total of 534 patients treated with liraglutide OD were included in the study. Patients treated with exenatide (n $=107$ ) and changed to liraglutide were excluded from the analysis. We report data from patients with a minimum treatment duration of 3 months $(n=346)$. In 83 patients liraglutide treatment was stopped due to adverse reactions or lack of clinical effect, and is omitted from the analyses. Baseline characteristics of patients treated with liraglutide $(\mathrm{n}=263$ ) were: age 57 (range: 29 - 84 years), body weight $106.9 \pm 21.7 \mathrm{~kg}$, BMI $35.4 \pm 6.4$ $\mathrm{kg} / \mathrm{m}^{2}$, HbA1c $8.7 \% \pm 1.5 \%(71 \pm 16 \mathrm{mmol} / \mathrm{mol})$ and diabetes duration was 7.0 years (range $0.1-30.5$ years).

\subsection{Liraglutide as Add-on to Oral Antidiabetic Agents (Table 1)}

One hundred and forty-nine patients (91 men) were treated with a combination of oral antidiabetic agents and liraglutide. Baseline age was $56 \pm 10.4$ years, and diabetes duration $7.3 \pm 6.0$ years. Before start of liraglutide 138 patients were treated with metformin with a median dose of $2000 \mathrm{mg}$ (range 1000 - $3000 \mathrm{mg}$ ), 86 patients with metformin and sulfonylurea (SU), eight patients with SU as mono-therapy, and 16 patients with a combination of metformin, SU and a dipeptidyl peptidase-IV (DPP-IV) inhibitor, which was stopped, when liraglutide OD treatment was inititated. Five patients were treated with rosiglitazone and one with repaglinide.

Mean follow up period was $7.3 \pm 3.0$ months with a maximum of 15 months. HbA1c before initiation of liraglutide was $8.7 \% \pm 1.5 \%$ (71 $\pm 16 \mathrm{mmol} / \mathrm{mol}$ ) ranging from $5.0 \%$ to $13.5 \%$ (31 to $124 \mathrm{mmol} / \mathrm{mol})$. Liraglutide treatment resulted in a $1.3 \% \pm 1.5 \%(15 \pm 16 \mathrm{mmol} / \mathrm{mol})$ reduction in HbA1c $(\mathrm{P}<0.001)$, and $43 \%(\mathrm{n}=64)$ of patients achieving $\mathrm{HbAlc} \leq 7.0 \%(53 \mathrm{mmol} / \mathrm{mol})$. Thirty-seven patients $(25 \%)$ reached $\mathrm{HbAlc} \leq 6.5 \%(48$ $\mathrm{mmol} / \mathrm{mol})$. Mean weight reduction was $-3.5 \pm 4.1 \mathrm{~kg}$ from $105.2 \pm 21.3 \mathrm{~kg}(\mathrm{P}<0.001)$. Divided into weight response quartiles mean weight changes were $-8.9 \pm 2.7 \mathrm{~kg},-4.3 \pm 0.7 \mathrm{~kg},-1.8 \pm 0.8 \mathrm{~kg}$ and $1.3 \pm 1.9 \mathrm{~kg}$. Body mass index was reduced with $-1.1 \pm 1.7 \mathrm{~kg} / \mathrm{m}^{2}$ from a baseline BMI of $34.8 \pm 6.4 \mathrm{~kg} / \mathrm{m}^{2}$.

Median liraglutide dose was $1.2 \mathrm{mg}$ OD, range $0.6 \mathrm{mg}$ - $2.4 \mathrm{mg}$. Most patients were treated with $1.2 \mathrm{mg}$ (79\%) and $19 \%$ with $1.8 \mathrm{mg}$ liraglutide. In the groups treated with liraglutide $1.2 \mathrm{mg}$ and $1.8 \mathrm{mg}$ the reduction in HbA1c and weight did not differ significantly.

In patients treated with SU at baseline $(n=94$, mainly glimepiride $(n=69)), 35$ patients continued therapy with no dose adjustment, however in 22 patients SU treatment was stopped. In 31 patients the SU dosage could be reduced with between $-33 \%$ to $-75 \%$. In four patients SU dosage were increased during the follow-up period, and in one patient dose of SU was unknown. In patients with duration of diabetes $<10$ years compared to $>10$ years, the reduction in HbA1c and weight loss did not differ.

Table 1. Baseline characteristics and the effect of adding liraglutide to oral antidiabetic agents (OOA) or insulin after 7.3 $( \pm 3.0)$ and $7.0( \pm 3.1)$ months follow-up, respectively.

\begin{tabular}{|c|c|c|}
\hline & OAA + liraglutide & insulin + liraglutide \\
\hline Number (n) & 149 & 114 \\
\hline Sex (\% males) & 61 & 59 \\
\hline Age (years) & $56( \pm 10.4)$ & $59( \pm 10.4)$ \\
\hline Diabetes duration (years) & $7.3( \pm 6.0)$ & $9.8(0-30)^{+}$ \\
\hline $\mathrm{BMI}\left(\mathrm{kg} / \mathrm{m}^{2}\right)$ & $34.8( \pm 6.4)$ & $36.5( \pm 6.4)$ \\
\hline $\mathrm{HbA} 1 \mathrm{c}(\%) /(\mathrm{mmol} / \mathrm{mol})$ & $8.7( \pm 1.5) / 71( \pm 16)$ & $8.7( \pm 1.5) / 71( \pm 16)$ \\
\hline Reduction in HbA1c (\%)/(mmol/mol) & $-1.3( \pm 1.5) /-15( \pm 16)^{*}$ & $-0.8( \pm 1.2) /-8( \pm 13)^{*}$ \\
\hline Body weight (kg) & $105.2( \pm 21.3)$ & $109.2( \pm 22.1)$ \\
\hline Reduction in body weight (kg) & $-3.5( \pm 4.1)^{*}$ & $-5.1( \pm 4.9)^{*}$ \\
\hline
\end{tabular}

All numbers are means $( \pm \mathrm{SD})$ unless otherwise stated. ${ }^{*} \mathrm{p}<0.001 ;+$ median (range). 


\subsection{Liraglutide as Add-on to Insulin (Table 1)}

Liraglutide was add-on to insulin in 114 patients (67 men) with an average age of $59 \pm 10.4$ years and a median duration of diabetes of 9.8 years, (range 0 - 30 years), where 99 patients at the same time were treated with metformin with a median dose of $2000 \mathrm{mg}$ (range 500 - $3000 \mathrm{mg}$ ). Fifteen patients were treated with a SU, predominantly glimipiride with a median dose of $4 \mathrm{mg}$ (range $2-6 \mathrm{mg}$ ). Treatment with a DPP-4 inhibitor was stopped in all patients before initiation of treatment with liraglutide.

Patients were treated with insulin premix $(n=39)$, insulin glargine $(n=32)$, intermediate acting NPH insulin $(n=15)$, combination of glargine and insulin aspart $(n=12)$ and five patients were treated with insulin detemir. The rest of the patients were treated with various combinations of the mentioned insulins and rapid acting human insulin.

Mean follow up was $7.0 \pm 3.1$ months with a maximum of 15 months. Baseline mean HbA1c before initiating treatment with liraglutide was $8.7 \% \pm 1.5 \%$ (71 $\pm 16 \mathrm{mmol} / \mathrm{mol})$, ranging from $6 \%$ to $13.4 \%$ (42 to 123 $\mathrm{mmol} / \mathrm{mol})$. Addition of liraglutide to insulin therapy resulted in a $0.8 \% \pm 1.2 \%(8 \pm 13 \mathrm{mmol} / \mathrm{mol})$ reduction in HbA1c ( $<<0.001)$. Before start of liraglutide treatment $12 \%$ of the patients had a HbA1c $\leq 7.0 \%(53$ $\mathrm{mmol} / \mathrm{mol}$ ), and 30\% achieved a HbAlc $\leq 7.0 \%$ (53 $\mathrm{mmol} / \mathrm{mol})$ during treatment with liraglutide, and $12 \%$ a $\mathrm{HbA} 1 \mathrm{c} \leq 6.5 \%(48 \mathrm{mmol} / \mathrm{mol})$.

The mean body mass index was $36.5 \pm 6.4 \mathrm{~kg} / \mathrm{m}^{2}$ and was reduced by $1.7 \pm 1.8 \mathrm{~kg} / \mathrm{m}^{2}$ (p $\left.<0.001\right)$. Mean weight loss was $5.1 \pm 4.9 \mathrm{~kg}$ from $109.2 \pm 22.1 \mathrm{~kg}(\mathrm{p}<0.001)$, corresponding to a mean reduction of $4.8 \% \pm 4.6 \%$ of baseline weight. The mean weight loss in the quartiles with the greatest weight change was $-11.5 \pm 3.0 \mathrm{~kg}$, and $-6.4 \pm 0.8 \mathrm{~kg},-3.4 \pm 1.0 \mathrm{~kg}$ and $0.9 \pm 1.8 \mathrm{~kg}$. The reduction in weight was not correlated with the reduction in $\mathrm{HbA} 1 \mathrm{c}$.

Median liraglutide dose was $1.2 \mathrm{mg}$ OD (range 0.6 - $2.4 \mathrm{mg}$ ), and 61\% ( $=69)$ were treated with $1.2 \mathrm{mg}$ and $32 \%(n=37)$ with $1.8 \mathrm{mg}$. The reduction in HbA1c and in weight did not differ between patients treated with $1.2 \mathrm{mg}$ versus $1.8 \mathrm{mg}$.

Insulin dose at baseline was $83 \pm 59$ U/day, (range 8 - 300 U/day). During treatment with liraglutide the mean reduction in insulin dose was $28.1 \pm 36$ U/day (range 8 -160 IU/day), and insulin treatment was stopped in $19 \%$ $(n=22)$ of the patients. The mean reduction in dose of insulin in the $1.8 \mathrm{mg}$ group was slightly larger than in the $1.2 \mathrm{mg}$, but not significantly $(\mathrm{p}<0.09)$. We found a significant $(\mathrm{p}=0.05)$ and positive correlation $(\mathrm{r}=0.38)$ between reduction in daily dose of insulin and weight loss, but no significant correlation between duration of diabetes and weight loss or reduction in dose of insulin.

In the 22 patients in whom insulin treatment could be stopped, the median liraglutide dose was $1.2 \mathrm{mg}$ OD (range 1.2 - $1.8 \mathrm{mg}$ ). In one patient the dose was unknown. The mean age was $57.5 \pm 13.1$ years, and median diabetes duration of 6.8 years (range 0 - 30 years). The follow-up was $8.1 \pm 3.2$ months (range 3 - 12 months), and baseline $\mathrm{HbA} 1 \mathrm{c}$ was $7.6 \% \pm 1.0 \%$ (60 $\pm 10 \mathrm{mmol} / \mathrm{mol})$, with a reduction in HbA1c of $0.4 \% \pm 1.0 \%(4 \pm 10$ $\mathrm{mmol} / \mathrm{mol}$ ), and in weight of $6.2 \pm 5.6 \mathrm{~kg}$, from a baseline weight of $102.8 \pm 24.5 \mathrm{~kg}$, range $75-155 \mathrm{~kg}$. Baseline insulin dose was $43 \pm 31 \mathrm{U} /$ day, ranging from 12 to $160 \mathrm{U} /$ day. In four patients insulin therapy had to be initiated during the observation period. In two patients (SU) treatment could be ended as well, and in 3 patients SU treatment had to be initiated.

\subsection{Adverse Events}

A total of 83 patients stopped treatment with liraglutide in the follow-up period. In 21 patients liraglutide was stopped due to lack of clinical significant effect on HbA1c or weight or failure to reduce amount of insulin. Most patients $(n=34)$ stopped liraglutide treatment due to gastrointestinal (GI) side effects. Thus, 20 patients experienced nausea, 10 patients diarrhea, eight patients had vomiting, six abdominal pains, two patients constipation, one patients dyspepsia and five patients unspecified GI side effects. Twenty patients stopped liraglutide treatment due to other adverse events or causes including headache, tooth pain, discomfort, dizziness and fatigue. Two patients stopped liraglutide treatment after bariatric surgery and one due to pregnancy. Only one patient stopped liraglutide treatment because of hypoglycaemia. Eleven patients experienced more than one side effect. No cases of pancreatitis were diagnosed, but 3 patients were diagnosed with cancer in the follow up period, and liraglutide treatment terminated: two cases of esophagus cancer and one case of metastases to the liver with unknown primary tumor at time of follow-up. In seven patients the cause of stopping treatment could not be identified. 


\section{Discussion}

While GLP-1 receptor agonists have been studied in clinical trials, reports on their efficacy in real world clinical practice are limited. In the present audit 346 patients, who had been followed for more than three months, liraglutide was added on to oral antidiabetic agents in 149 patients, resulting in a mean reduction of HbA1c of $1.3 \%$ (15 mmol/mol) from a baseline level of $8.7 \%(71 \mathrm{mmol} / \mathrm{mol})$, despite SU were stopped in 54 patients, and $43 \%$ of patients achieved $\mathrm{HbA} 1 \mathrm{c} \leq 7.0 \%$ (53 $\mathrm{mmol} / \mathrm{mol})$. Mean weight reduction was $3.5 \mathrm{~kg}$. Surprisingly, liraglutide was from time of approval used off label as add-on to insulin in 114 patients with a mean baseline HbA1c of $8.7 \%$ (71 mmol/mol). The reduction in $\mathrm{HbA1c}$ was $0.8 \%(8 \mathrm{mmol} / \mathrm{mol})$ in spite of a reduction in baseline dose of insulin of $83 \mathrm{U} /$ day with $28 \mathrm{U} /$ day. Insulin treatment could be stopped in 19\% of the patients. Weight loss was on the average $5.1 \mathrm{~kg}$ after a mean follow-up of 7 months. We did not find any correlation between duration of diabetes and weight loss or HbA1c reduction in the two groups. In the insulin treated patients a positive correlation between weight loss and reduction in dose of insulin was demonstrated. Eighty-three patients stopped treatment with liraglutide because of side effects or due to lack of a clinical significant effect on HbA1c or weight. The majority of side effects in these patients was gastrointestinal adverse effects, which is the events reported most frequently in clinical trials [1] [2]. Today, our experience is, that gastrointestinal side effects can be minimized by use of a slower up-titration with less doses of liraglutide than suggested by the pharmaceutical company. The efficacy of liraglutide in relation to HbA1c and weight loss in the group treated with oral antidiabetic drugs is quite similar to the results from the LEAD studies [1] [2]. In the LEAD studies liraglutide was evaluated in monotherapy or in combination with one or two oral antidiabetic agents [2]. The mean age was about 52 to 58 years, mean duration of diabetes 5.2 to 9.7 years, body mass index 29.4 to $33.9 \mathrm{~kg} / \mathrm{m}^{2}$ and basal HbA1c 8.1\% to 8.6\% [2]. Most studies were of 26 weeks duration except LEAD 3, which has a duration of 52 weeks [2]. The absolute reduction on HbA1c was from $1.2 \%$ to $1.5 \%$, with the greatest reduction with $1.8 \mathrm{mg}$ compared with $1.2 \mathrm{mg}$ of liraglutide except for the LEAD 2 study, where liraglutide was add-on to metformin [2]. In the LEAD 2 study the reduction in HbA1c did not differ in patients treated with $1.2 \mathrm{mg}$ vs. $1.8 \mathrm{mg}$ of liraglutide. In LEAD 5, where liraglutide $1.8 \mathrm{mg}$ was added to metformin plus sulfonylurea, as in most patients in the present study, the HbA1c reduction was 1.3\% [2]. The weight loss in the LEAD studies was dose-dependent, and the mean weight loss ranges from no weight loss with $1.2 \mathrm{mg}$ in LEAD 1 (add-on to glimepiride) to around $3 \mathrm{~kg}$ in LEAD 6 [2]. On the average the weight loss was about 2 - $3 \mathrm{~kg}$ and greater in people with a higher body mass [2]. Noteworthy, the majority of the patients in the present study were treated with 1.2 mg liraglutide daily. Our patients were more obese than in the LEAD studies, and the mean weight loss seems to be greater than in most studies in the LEAD program, although as in the LEAD studies one quarter of the patients did not lose weight [1] [2] The weight loss in the present study may in part also be explained by the large number of patients, who reduced or terminated treatment with SU.

The reduction in weight was even greater when liraglutide was used as add-on to insulin treatment, probably explained by the combined action of liraglutide per se on appetite and the reduction in daily dose of insulin. One quarter of the patients lost approximately $11 \mathrm{~kg}$ in body weight and about $20 \%$ of the patients could stop insulin treatment. We found some correlation between weight loss and reduction in daily insulin dose.

In a recent study from Wales, UK, 256 type 2 diabetic patients started treatment with liraglutide in routine clinical practice [15]. After a median follow-up of 48 weeks the reduction in HbA1c was $1.22 \%$ (13 mmol/mol) and in weight $3.9 \mathrm{~kg}$ [15]. Similar results was reported from three outpatients clinics in North-East Italy, where 166 type 2 diabetic patients initiated treatment with liraglutide and followed for 9.4 months [16]. The reduction in $\mathrm{HbA} 1 \mathrm{c}$ was $1.5 \%$ (16 mmol/mol) and in weight $4.0 \mathrm{~kg}$. Most patients (74\%) both lost weight and reduced HbA1c [16]. In the nationwide audit conducted by the Association of British Clinical Diabetologists (ABCD) adding exenatide BID to insulin resulted in a $0.5 \%$ (6 mmol/mol) reduction in $\mathrm{HbA1c}$ and a weight loss of 5.8 $\mathrm{kg}$, while insulin dose was reduced from $120 \mathrm{U} /$ day to $78 \mathrm{U} /$ day after more than 6 months follow-up [17]. Several other studies where exenatide BID was used as add-on to insulin reported beneficial effects on both HbA1c and weight [18]-[25]. In general, the titration schemes of insulin in the different studies are unknown, and all studies are without a control group. In some of the studies with the largest reduction in weight also reported significant reduction in total insulin dose, and especially in postprandial insulin dose [18]-[25]. Collectively, the studies aiming primary to improve glycaemic control with no or minimal down-titration of insulin demonstrated the least weight loss when exenatide BID was added to insulin therapy, while studies focusing on insulin sparing tended to show greater weight loss and more modest glycaemic benefits [18]-[25]. 
Buse et al. conducted the first double-blind clinical trial adding exenatide BID to insulin glargine in obese people with advanced type 2 diabetes with a mean duration of diabetes of 12 years and a baseline HbA1c of 8.4\% $(68 \mathrm{mmol} / \mathrm{mol})$ [14]. After 30 weeks of treatment with exenatide or placebo, the exenatide group obtained a decrease of $-1.7 \%(19 \mathrm{mmol} / \mathrm{mol})$ in $\mathrm{HbA} 1 \mathrm{c}$ and $-1.8 \mathrm{~kg}$ in weight, compared to a reduction of $-1.0 \%$ (11 $\mathrm{mmol} / \mathrm{mol}$ ) in $\mathrm{HbA} 1 \mathrm{c}$ and a weight gain of $0.96 \mathrm{~kg}$ in the placebo group. The decrease in fasting plasma glucose was similar for both groups, morning and evening postprandial plasma glucose, however, was lower in the exenatide group. The increase in insulin doses was $13 \mathrm{U} /$ day vs. $20 \mathrm{U} /$ day, respectively. The risk of hypoglycaemia did not differ between the two groups. The modest decrease in weight in the exenatide group may be explained by the up-titration of the dose of insulin to optimize glycaemic control [14]. Recently, Riddle et al. added the short acting once-daily GLP-1 receptor agonist lixisenatide to basal insulin and demonstrated a placebo corrected reduction in $\mathrm{HbA} 1 \mathrm{c}$ of $0.4 \%$ (4 mmol/mol), a weight loss of $-1.3 \mathrm{~kg}$ and a reduction in daily dose of insulin of $3.7 \mathrm{U} /$ day after 24 weeks of treatment [26]. The results may indicate, that the short acting GLP-1 receptor agonists (exenatide and lixisenatide) need to be administered twice daily to optimize their potential for improving glycaemic control and weight loss in combination with insulin treatment. A limitation of the present study is that it is a retrospective analysis and the lack of a control group. We did not have a specific algorithm for introducing liraglutide treatment to insulin treated patients, it was up to the treating physicians clinical judgement. Another limitation is that the occurrence of hypoglycaemia was not registered, which could be a potential problem when combining a GLP-1 receptor agonist with insulin. Neither did we quantify the amount of patients with poor compliance, which ultimately could lead to underestimation of the effect of liragutide. The patients who stopped treatment with liraglutide were not included in the analyses of the effect of liraglutide on HbA1c and weight, why the beneficial effect of liraglutide is overestimated. Nevertheless, our analyses demonstrate the utility of liraglutide in routine practice from time of approval, and contribute to the evaluation of the positioning of liraglutide in the type 2 diabetes treatment algorithm.

\section{Conclusion}

Liraglutide is indicated for treatment of hyperglycemia in type 2 diabetic patients on oral antidiabetic medication. This will in the majority of patients induce weight loss and a reduction in HbA1c. Most frequent adverse event leading to discontinuation of liraglutide treatment was gastrointestinal symptoms. Liraglutide was used off-label in combination with insulin. This combination has several potential advantages, including decreased exogenous insulin requirement, weight loss in most patients and improved glycaemic control.

\section{References}

[1] Perry, C.M. (2011) Liraglutide: A Review of Its Use in the Management of Type 2 Diabetes Mellitus. Drugs, 71, 23472373. http://dx.doi.org/10.2165/11208110-000000000-00000

[2] Madsbad, S. (2009) Exenatide and Liraglutide: Different Approaches to Develop GLP-1 Receptor Agonists (Incretinmimetics) —Preclinical and Clinical Results. Best Practice \& Research Clinical Endocrinology \& Metabolism, 23, 463-477. http://dx.doi.org/10.1016/j.beem.2009.03.008

[3] Holst, J.J. (2007) The Physiology of Glucagon-Like Peptide 1. Physiological Reviews, 87, 1409-1439. http://dx.doi.org/10.1152/physrev.00034.2006

[4] Jelsing, J., Vrang, N., Hansen, G., Raun, K., Tang-Christensen, M. and Knudsen, L.B. (2012) Liraglutide: Short-Lived Effect on Gastric Emptying-Long Lasting Effects on Body Weight. Diabetes, Obesity and Metabolism, 14, 531-538. http://dx.doi.org/10.1111/j.1463-1326.2012.01557.x

[5] Madsbad, S. (2012) Dipeptidyl Peptidase-4 (DPP-4) Inhibitors Are Favourable to Glucagon-Like Peptide-1 (GLP-1) Agonists. European Journal of Internal Medicine, 23, 132-136. http://dx.doi.org/10.1016/j.ejim.2011.11.003

[6] Flint, A., Kapitza, C. and Zdravkovic, M. (2013) The Once-Daily Human GLP-1 Analogue Liraglutide Impacts Appetite and Energy Intake in Patients with Type 2 Diabetes after Short-Term Treatment. Diabetes, Obesity and Metabolism, 15, 958-962. http://dx.doi.org/10.1111/dom.12108

[7] Niswender, K., Pi-Sunyer, X., Buse, J., Jensen, K.H., Toft, A.D., Russell-Jones, D., et al. (2013) Weight Change with Liraglutide and Comparator Therapies: An Analysis of Seven Phase 3 Trials from the Liraglutide Diabetes Development Programme. Diabetes, Obesity and Metabolism, 15, 42-54. http://dx.doi.org/10.1111/j.1463-1326.2012.01673.x

[8] Nauck, M., Brandle, M., Vaag, A., Colagiuri, S., Schmitz, O., Zdravkovic, M., et al. (2008) The Once-Daily Human GLP-1 Analogliraglutide Substantially Reduces HbA(1c) in Subjects with Type 2 Diabetes, Irrespective of HbA(1c) at Baseline. Diabetes, 57, A594. 
[9] DeFronzo, R.A. (2009) Banting Lecture. From the Triumvirate to the Ominous Octet: A New Paradigm for the Treatment of Type 2 Diabetes Mellitus. Diabetes, 58, 773-795. http://dx.doi.org/10.2337/db09-9028

[10] Inzucchi, S.E., Bergenstal, R.M., Buse, J.B., Diamant, M., Ferrannini, E., Nauck, M., et al. (2012) Management of Hyperglycemia in Type 2 Diabetes: A Patient-Centered Approach: Position Statement of the American Diabetes Association (ADA) and the European Association for the Study of Diabetes (EASD). Diabetes Care, 35, 1364-1379.

[11] Hemmingsen, B., Christensen, L.L., Wetterslev, J., Vaag, A., Gluud, C., Lund, S.S., et al. (2012) Comparison of Metformin and Insulin versus Insulin Alone for Type 2 Diabetes: Systematic Review of Randomised Clinical Trials with Meta-Analyses and Trial Sequential Analyses. BMJ, 344, e1771.

[12] Holman, R.R., Thorne, K.I., Farmer, A.J., Davies, M.J., Keenan, J.F., Paul, S., et al. (2007) Addition of Biphasic, Prandial, or Basal Insulin to Oral Therapy in Type 2 Diabetes. The New England Journal of Medicine, 357, 1716-1730. http://dx.doi.org/10.1056/NEJMoa075392

[13] Rosenstock, J., Davies, M., Home, P.D., Larsen, J., Koenen, C. and Schernthaner, G. (2008) A Randomised, 52-Week, Treat-to-Target Trial Comparing Insulin Detemir with Insulin Glargine When Administered as Add-On to GlucoseLowering Drugs in Insulin-Naive People with Type 2 Diabetes. Diabetologia, 51, 408-416. http://dx.doi.org/10.1007/s00125-007-0911-x

[14] Buse, J.B., Bergenstal, R.M., Glass, L.C., Heilmann, C.R., Lewis, M.S., Kwan, A.Y., et al. (2011) Use of TWICEDaily Exenatide in Basal Insulin-Treated Patients with Type 2 Diabetes: A Randomized, Controlled Trial. Annals of Internal Medicine, 154, 103-112. http://dx.doi.org/10.7326/0003-4819-154-2-201101180-00300

[15] Evans, M., McEwan, P., O’Shea, R. and George, L. (2013) A Retrospective, Case-Note Survey of Type 2 Diabetes Patients Prescribed Incretin-Based Therapies in Clinical Practice. Diabetes Therapy, 4, 27-40. http://dx.doi.org/10.1007/s13300-012-0015-6

[16] Fadini, G.P., Simioni, N., Frison, V., Dal, P.M., Bettio, M., Rocchini, P., et al. (2013) Independent Glucose and Weight-Reducing Effects of Liraglutide in a Real-World Population of Type 2 Diabetic Outpatients. Acta Diabetologica, 50, 943-949. http://dx.doi.org/10.1007/s00592-013-0489-3

[17] Thong, K.Y., Jose, B., Sukumar, N., Cull, M.L., Mills, A.P., Sathyapalan, T., et al. (2011) Safety, Efficacy and Tolerability of Exenatide in Combination with Insulin in the Association of British Clinical Diabetologists Nationwide Exenatide Audit. Diabetes, Obesity and Metabolism, 13, 703-710. http://dx.doi.org/10.1111/j.1463-1326.2011.01393.x

[18] Levin, P., Wei, W., Wang, L., Pan, C., Douglas, D. and Baser, O. (2012) Combination Therapy with Insulin Glargine and Exenatide: Real-World Outcomes in Patients with Type 2 Diabetes. Current Medical Research and Opinion, 28, 439-446. http://dx.doi.org/10.1185/03007995.2012.654850

[19] Nayak, U.A., Govindan, J., Baskar, V., Kalupahana, D. and Singh, B.M. (2010) Exenatide Therapy in Insulin-Treated Type 2 Diabetes and Obesity. QJM: An International Journal of Medicine, 103, 687-694. http://dx.doi.org/10.1093/qjmed/hcq112

[20] Pawaskar, M., Li, Q., Hoogwerf, B.J., Reynolds, M.W., Lee, L.J. and Fonseca, V. (2012) Clinical Outcomes of Concomitant Therapy of Exenatide Twice Daily and Basal Insulin in Patients with Type 2 Diabetes Mellitus: A Retrospective Database Analysis in the United States. Endocrine Practice, 18, 700-711. http://dx.doi.org/10.4158/EP11367.OR

[21] Sheffield, C.A., Kane, M.P., Busch, R.S., Bakst, G., Abelseth, J.M. and Hamilton, R.A. (2008) Safety and Efficacy of Exenatide in Combination with Insulin in Patients with Type 2 Diabetes Mellitus. Endocrine Practice, 14, $285-292$. http://dx.doi.org/10.4158/EP.14.3.285

[22] Viswanathan, P., Chaudhuri, A., Bhatia, R., Al-Atrash, F., Mohanty, P. and Dandona, P. (2007) Exenatide Therapy in Obese Patients with Type 2 Diabetes Mellitus Treated with Insulin. Endocrine Practice, 13, 444-450. http://dx.doi.org/10.4158/EP.13.5.444

[23] Yoon, N.M., Cavaghan, M.K., Brunelle, R.L. and Roach, P. (2009) Exenatide Added to Insulin Therapy: A Retrospective Review of Clinical Practice over Two Years in an Academic Endocrinology Outpatient Setting. Clinical Therapeutics, 31, 1511-1523. http://dx.doi.org/10.1016/j.clinthera.2009.07.021

[24] Davis, S.N., Johns, D., Maggs, D., Xu, H., Northrup, J.H. and Brodows, R.G. (2007) Exploring the Substitution of Exenatide for Insulin in Patients with Type 2 Diabetes Treated with Insulin in Combination with Oral Antidiabetes Agents. Diabetes Care, 30, 2767-2772. http://dx.doi.org/10.2337/dc06-2532

[25] Thong, K.Y., Jose, B., Blann, A.D., Cull, M.L., Mills, A.P., Sathyapalan, T., et al. (2011) Response at 3 Months to Insulin Dose Decisions Made at Exenatide Initiation in the Association of British Clinical Diabetologists (ABCD) Nationwide Exenatide Audit. Diabetes Research and Clinical Practice, 93, e87-e91. http://dx.doi.org/10.1016/j.diabres.2011.05.015

[26] Riddle, M.C., Aronson, R., Home, P., Marre, M., Niemoeller, E., Miossec, P., et al. (2013) Adding Once-Daily Lixisenatide for Type 2 Diabetes Inadequately Controlled by Established Basal Insulin: A 24-Week, Randomized, PlaceboControlled Comparison (GetGoal-L). Diabetes Care, 36, 2489-2496. http://dx.doi.org/10.2337/dc12-2454 